\title{
A NEURO FUZZY MODEL FOR THE INVESTIGATION OF DETERIORATION OF METALLIC PIPE CONVEYING FLUID UNDER DIFFERENT PIPE BURIAL DEPTH, SOIL TYPES AND PROPERTIES
}

\author{
T. T. Akano ${ }^{1,{ }^{*}}$, 0. A. Fakinlede ${ }^{2}$, H. E. Mgbemere ${ }^{3}$ and J. C. Amechi ${ }^{4}$

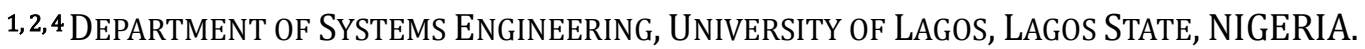 \\ ${ }^{3}$ DePARTMENT OF METAlLURGiCAl AND MATERIALS ENGINEERING, UNIVERSITY OF LAGOS, LAGOS STATE, NIGERIA. \\ E-mail addresses: ${ }^{1}$ takano@unilag.edu.ng,2oafak@unilag.edu.ng,3hmgbemere@unilag.edu.ng, \\ 4 amechijide@gmail.com
}

\begin{abstract}
Several factors may contribute directly or indirectly to the structural failure of metallic pipes. The most important of which is corrosion. Corrosivity of pipes is not a directly measurable parameter as pipe corrosion is a very random phenomenon. The main aim of the present study is to develop a neuro-fuzzy model capable of establishing corrosion rate criterion as a function of pipe burial depth, soil types, and properties for the prediction of deterioration of metallic pipe conveying fluid. The proposed model includes a fuzzy model and the artificial neural network (ANN) to determine soil corrosivity potential (CoP) based on soil properties. The combination contains the data of linguistic variables characterising various soil properties, and learning capability of the system that constructs relationships among those soil properties and CoP. Subsequently, the artificial neuro-fuzzy inference system (ANFIS) maps each element of its input membership function to an output membership function between $O$ and 1 to determine the deterioration rate (CoP) of metallic fluid-conveying-pipe. Field data from buried fluid pipes were examined to illustrate the application of the proposed model. The ultimate goal is the ability to access the current and future life of oil pipe, given a set of circumstances, and also appropriate adoptable methodology in view of a preventive maintenance measure for the pipes in a given operating environment. Results reveal that with more than $40 \%$ clay content quickens corrosion of buried fluid pipes more than any other considered factor.
\end{abstract}

Keywords: neuro-fuzzy, corrosivity potential, deterioration, metallic pipe, soil, deterioration rate

\section{INTRODUCTION}

Pipeline corrosion is a natural deterioration that leads to destruction of pipe material and essential properties. This is due to electrochemical and other ingredient reactions of pipeline materials with their environment as well as outside surfaces [1]. A typical example of pipe corrosion is shown in Figure 1.

Different mathematical and statistical techniques have been developed to model pipe deterioration. Research work by [2] and [3] gave exhaustive examples of such modelling techniques to include but not limited to deterministic, probabilistic/statistical, artificial intelligence based, and combined artificial intelligencebased models. Combined and artificial intelligence-based model has the advantage of being insensitive to noisy data, automatic detection of non-linear underlying processes, and ability to handle both scale and ordinal data types.
In recent years, fuzzy-based methods have increasingly been applied to civil and environmental engineering problems from the evaluation of concrete structures to water quality modelling [5-7].

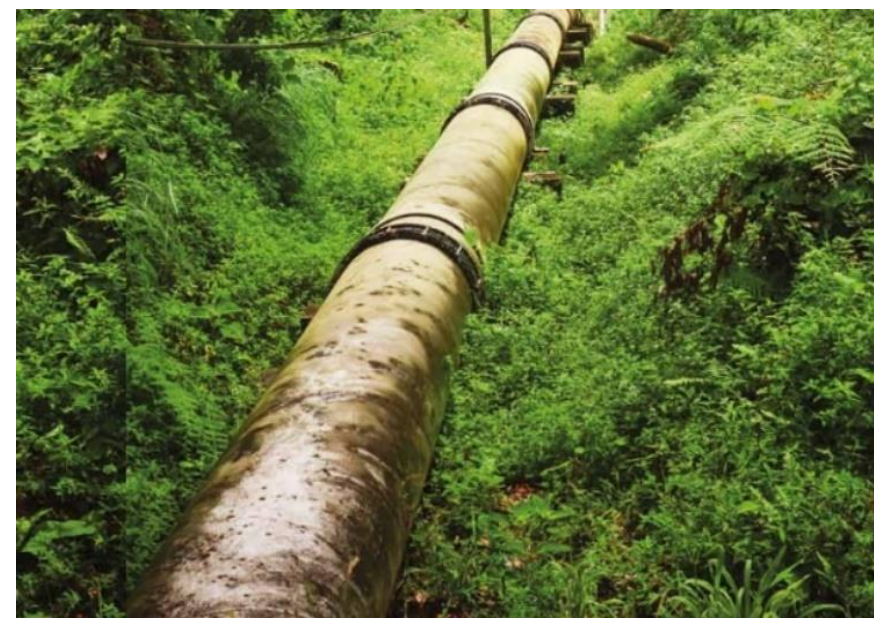

Figure 1: Pipeline external corrosion [4] 
In many engineering problems, the available information is vague. Sometime measured data or even expert knowledge is too imprecise to justify the use of numbers. Fuzzy logic provides a language with syntax and semantics to translate qualitative knowledge into numerical reasoning. Combined artificial intelligencebased model such as NFM is based on two powerful artificial intelligence techniques, the multi-valued logical system (fuzzy logic) to account for noisy data and neural networks to map input factors to accurate outputs (i.e. structural condition), taking the optimal advantages of both models for best output.

The economic and social cost of pipe failures is increasing, putting pressure on utility managers to develop annual replacement plans for critical pipes that balance investment with expected benefits in a riskbased management context. In addition to the need for a strategy for solving such a multi-objective problem, analysts and utility managers need reliable and robust failure models for assessing network performance. Hence, this paper presents the application of an NFM to estimate the metallic fluid-conveying-pipe deterioration rate using a neuro-fuzzy model that relates pipes' external corrosion to its burial depth and surrounding soil properties.

The first step towards determining the corrosion allowance should be the establishment of a link between some measurable properties of the pipeline soil environment and the resulting corrosion rate [8-10]. There are essentially three different approaches that can be taken to establish this link. First is the empirical correlations to actual measurements of corrosion damage in steel pipes exposed to representative soils. Next is the development of laboratory measurements and models for estimation, and lastly is to establish detailed computer models with valid assumptions for ratedetermining processes. Each of these different approaches has advantages and drawbacks. However, they all require verification with actual data from exposure tests on samples in representative soil environments. Soils are composed of essentially three features: the mineral particulates, organic matter from surface and subsurface plant and animal life, and groundwater containing soluble salts and gases. The particulate matter found in soils is usually small particles of the minerals found in the nearby rock formations. They are produced over millions of years of weathering and the decomposition process. In either case, most of the particles making up a soil are insoluble minerals, as most soluble species have been removed over the years of weathering [10-12]. The solubility of these minerals varies with $\mathrm{pH}$. This phenomenon tends to buffer the $\mathrm{pH}$ of the groundwater. However, if there are no significant changes in $\mathrm{pH}$ with time, it implies that the minerals behave as inert solids. For this work, the observed soil types were classified into six namely; Loamy Sand (LS), Silty Clay (SC), SdC (Sandy Clay), Sand (S), SCL (Silty Clay Loam) and Light Clay (LC) with an increasing clay content respectively. Hence, in this work, five soil properties will be considered: pipe burial depth, soil type (ranked by percentage clay), temperature, moisture content, and $\mathrm{pH}$ to detect the deterioration of buried metallic fluid-conveying-pipe as a result of corrosion.

Table 1: An Extract - data samples collected at Field sites

\begin{tabular}{|c|c|c|c|c|c|c|c|c|c|c|c|}
\hline \multirow[b]{2}{*}{$\begin{array}{l}\text { Pipe } \\
\text { Sites }\end{array}$} & \multicolumn{4}{|c|}{ Pipe details } & \multicolumn{5}{|c|}{ Environment } & \multirow[b]{2}{*}{$\begin{array}{l}\text { Corrosion } \\
\text { Form }\end{array}$} & \multirow[b]{2}{*}{$\begin{array}{l}\text { Detero. } \\
\text { Rate } \\
(\mathrm{mm} / \mathrm{yr})\end{array}$} \\
\hline & $\begin{array}{c}\text { Type } \\
\text { (\%carbon } \\
\text { @ avg. } \\
\text { of } 3 \% \text { ) }\end{array}$ & $\begin{array}{l}\text { Diameter } \\
(\mathrm{mm})\end{array}$ & $\begin{array}{l}\text { Thickness } \\
(\mathrm{mm})\end{array}$ & $\begin{array}{l}\text { Burial } \\
\text { Depth } \\
(\mathrm{mm})\end{array}$ & $\begin{array}{c}\text { Ground - } \\
\text { water } \\
(\mathrm{mm})\end{array}$ & $\begin{array}{c}\text { Soil } \\
\text { Texture }\end{array}$ & $\begin{array}{c}\text { Moisture } \\
\text { Content } \\
\text { (\% sat.) }\end{array}$ & $\mathrm{pH}$ & Temp. $\left({ }^{\circ} \mathrm{C}\right)$ & & \\
\hline 1 & CS & 500 & 14 & 500 & 750 & LS & 13.4 & 5.4 & 39 & I & 0.033 \\
\hline 2 & NC & 450 & 17 & 850 & 2000 & SC & 19.65 & 6.4 & 42 & G & 0.027 \\
\hline 3 & SD & 500 & 16.5 & 900 & 1400 & $\mathrm{SdC}$ & 18.30 & 6.3 & 35 & G & 0.042 \\
\hline 4 & CS & 500 & 14 & 600 & 1400 & $S$ & 11.25 & 5.3 & 40 & I & 0.054 \\
\hline 5 & SD & 250 & 13.2 & 400 & 2050 & SC & 19.45 & 7.3 & 34 & G & 0.077 \\
\hline 6 & NC & 450 & 17 & 850 & 2000 & SC & 19.65 & 6.4 & 36 & G & 0.037 \\
\hline 7 & SD & 500 & 17 & 1400 & 1650 & SC- & 26.65 & 7.9 & 37 & U & 0.062 \\
\hline 8 & CS & 300 & 11 & 600 & 900 & SCL & 22.05 & 8.3 & 34 & I & 0.054 \\
\hline 9 & $\mathrm{NC}$ & 375 & 18.5 & 500 & 2000 & SC & 22.25 & 5.1 & 48 & G & 0.077 \\
\hline 10 & CS & 375 & 18.5 & 1500 & 2075 & LC & 18.55 & 6.3 & 32 & G & 0.075 \\
\hline 11 & CS & 375 & 18.5 & 500 & 2050 & $\mathrm{SdC}$ & 15.15 & 7.9 & 38 & $G$ & 0.081 \\
\hline$\ldots$ & $\ldots$ & $\ldots$ & $\ldots$ & $\ldots$ & $\ldots$ & $\ldots$ & $\ldots$ & $\ldots$ & $\ldots$ &. & $\cdots$ \\
\hline$X x$ & $\mathrm{NC}$ & 600 & 22.2 & 650 & 2000 & SC & 19.35 & 5.6 & 41 & $G$ & 0.061 \\
\hline
\end{tabular}

Pipe Type: CS - cast iron, $S D$-standard ductile iron, $N C$ - nodular cast iron.

Soil Texture: LS - loamy sand, S - sand, SC- silty clay, SCL - silty clay loam, SdC-sandy clay, LC - light clay.

Corrosion Form: I-isolated pits, G-general pit clusters, U-unknown. 


\section{DATA COLLECTION AND SAMPLING}

The sites for burial of the samples were identified and selected to represent the different types of soils and conditions that could be found in Nigeria. The sites were identified by number, location, and soil type as shown in Table 1 below. The data was gotten from three major sources across Nigeria of which includes; Anambra Imo River Development Authority, Owerri (AIRBDA), Federal Institute of Industrial Research Oshodi, Lagos (FIIRO), International Institute for Tropical Agriculture, Ibadan (IITA) and Lagos State Material Testing Laboratory (LSMTL). However, smaller geo-technical Firms were consulted to validate the data collected.

In all cases the following procedure was used to obtain the samples. The fieldsmen were directed to take samples from the soil that surrounded the pipes and deposit them in plastic bags. They were also asked to "collect a soil sample close to the pipe, but not where the soil had been noticeably 'washed' by fluid (mostly water) from the pipe". All the pipe details, including the burial depth of the pipe and soil temperature at the time of data collection were recorded and the samples were immediately transported to the Labs for testing. After being received, a portion of each soil sample was placed in a separate sealed plastic bag to preserve the soil's moisture content, which was also ascertained. This sample was used to determine the soil's sulphide content and $\mathrm{pH}$. The remaining sample was used to classify the soil and measure its resistivity.

\section{MODEL IMPLEMENTATION}

The measurements for the analysis are standardised to non-dimensional forms and would produce an unbiased comparative graph. The Standard Score $Z_{i j}$ is given as,

$$
Z_{i j}=\left(\frac{x_{i j}-\mu_{x}}{\sigma_{x}}\right)
$$

Where $x_{i j}$ is measured value of the characteristic for the normal distribution and log of the measurement of the log-normal distribution, $\mu_{x}$ is the deviation, gives as,

$$
\mu_{x}=\frac{\sum(x-\mu)}{N}
$$

while $\sigma_{x}$ is the standard deviation, given as,

$$
\sigma_{x}=\sqrt{\frac{\sum(x-\mu)^{2}}{N}}
$$

The subscript $i$ means the $i^{t h}$ soil properties and $j$ represents the $j^{t h}$ number of sites; $N$ is the number of inputs samples. Thus, the standardised inputs are used to determine the degree to which they belong to each of the appropriate fuzzy sets via membership functions. In Matlab ANFIS Toolbox, the input is always at a crisp numerical value limited to the universe of discourse of the input variable which in this case is the interval between 0 and 10. The output is a fuzzy degree of membership in the qualifying linguistic set that is always at the interval between 0 and 1. Tables 2-6 are the input variables (i.e. membership functions used to determine the corrosivity potential) while Table 7 is the output membership function.

Table 2: Characterization of soil types based on percentage clay \begin{tabular}{cc}
\hline & percentage clay (soil particles \\
Soil Type & $<0.002 \mathrm{~mm}$ ) (by weight)
\end{tabular}

\begin{tabular}{lc}
\hline Granular material (gravel) & 15 \\
Sand & 22 \\
Silty sand & 25 \\
Silt & 30 \\
Silty clay & 35 \\
Clay & $>40$ \\
\hline \multicolumn{2}{c}{${ }^{*}$ corrosivity increases as the percentage clay increases } \\
\multicolumn{2}{c}{ Table 3: Various ranges of soil pH } \\
\hline $\mathrm{pH}$ & Degree of Corrosiveness \\
\hline $0-4.5$ & Corrosive \\
$4.5-7.5$ & Moderately Corrosive \\
$7.5-14$ & Least Corrosive \\
\hline
\end{tabular}

Table 4: Various degrees of temperature range

\begin{tabular}{cc} 
Temperature $\left({ }^{\circ} \mathrm{C}\right)$ & Degree of Corrosiveness \\
\hline $0-15$ & Inactive \\
$15-30$ & High \\
$30-45$ & Moderate \\
$45-60$ & Slightly Moderate \\
$60-70$ & Low \\
$75-80$ & Very Low
\end{tabular}

Table 5: Various degrees of moisture content range

\begin{tabular}{cc}
\hline $\begin{array}{c}\text { Moisture Content } \\
\text { \% Saturation })\end{array}$ & Degree of Corrosiveness \\
\hline $80-100$ & Generally Wet - Very Bad \\
$60-80$ & Fairly Wet - Bad \\
$40-60$ & Generally Moist - OK \\
$20-40$ & Fairly Dry - Good \\
$0-20$ & Generally Dry - Best \\
\hline
\end{tabular}

Table 6: Various degrees of corrosivity as a result of pipe burial

\begin{tabular}{cc}
\multicolumn{3}{c}{ depth } \\
\hline Burial Depth $(\mathrm{mm})$ & Corrosivity \\
\hline $500-750 \mathrm{~h}$ & Tolerable \\
$750-1000$ & Acceptable \\
$1000-1250$ & Appropriate \\
$1250-1500$ & Suitable \\
\hline
\end{tabular}

The input for the implication process is a single number given by the antecedent, and the output is a fuzzy set. The implication is implemented for each rule. Two built-in methods are supported, and they are the same functions that are used by the AND method: min (i.e. minimum), 


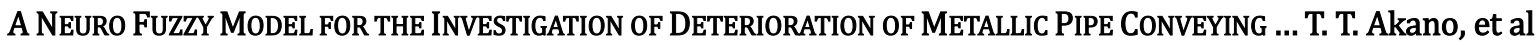

which truncates the output fuzzy set, and prod (product), which scales the output fuzzy set.

Table 7: Output Membership Function

\begin{tabular}{lc}
\hline $\operatorname{CoP}$ (output membership function) & Fuzzy Range \\
\hline Not Corrosive (NC) & $0.2-0.4$ \\
Slightly Corrosive (SC) & $0.4-0.6$ \\
Corrosive (Co) & $0.6-0.8$ \\
Highly Corrosive (HC) & $0.8-1.0$ \\
\hline
\end{tabular}

A popular defuzzification method is the centroid calculation, which returns the center of the area under the curve of the membership function associated with the aggregate output fuzzy set. There are five built-in methods supported: centroid, bisector, middle of maximum (which is the average of the maximum value of the output set), largest of maximum, and smallest of maximum. The adaptive neuro-fuzzy inference system is a class of adaptive networks that are functionally equivalent to fuzzy inference systems. The structure of ANFIS is shown in Figure 2. It also represents a SugenoTsukamoto fuzzy models that use a hybrid learning algorithm ([13], [14], [15]).

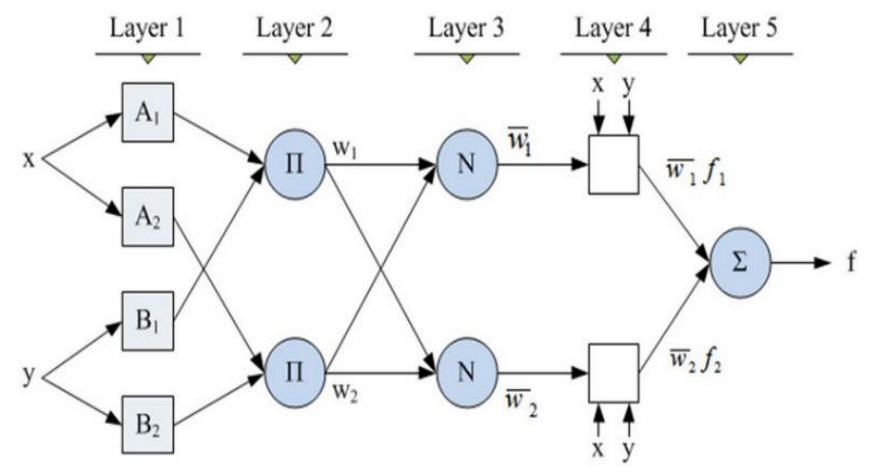

Figure 2: The ANFIS structure

Assuming that the ANFIS has two inputs, $x$ and one output $z$, the first-order model is given by:

Rule 1: If $x$ is $A_{1}$ and $y$ is $B_{1}$, then

$$
f_{1}=p_{1} x+q_{1} y+\eta
$$

Rule 2: If $x$ is $A_{2}$ and $y$ is $B_{2}$, then

$$
f_{2}=p_{2} x+q_{2} y+r_{2}
$$

Layer 1: $O_{1, i}$ is the output of the $i^{t h}$ node of the layer 1

$$
\begin{aligned}
& O_{1, i}=\mu A_{1}(x) \text { for } i=1,2, \text { or } \\
& O_{1, i}=\mu B_{1-2}(x) \text { for } i=3,4,
\end{aligned}
$$

$x$ (or $y$ ) is the input node $i$ and $A_{1} ; B_{1-2}$ is a linguistic label associated with this node.

Therefore, $O_{1, i}$ is a membership grade of a fuzzy set $\left(A_{1}, A_{2}, B_{1}, B_{2}\right)$. A typical membership function is described as;

$$
\mu A_{1}(x)=\frac{1}{1+2 \frac{x-c}{a_{i}} b_{i}}
$$

where $a, b, c$ is the parameter set, referred to as the premise parameters.

Layer 2: The output is the product of all the incoming signals. Each node represents the fire strength of the rule. Any other $T$-norm operator that performs the $A N D$ operator can be used.

$$
O_{2, i}=\hat{W}_{1}=\mu A_{1}(x) \cdot \mu B_{1}(y) \text { for } i=1,2
$$

Layer 3: Every node in this layer is a fixed node labelled Norm. The $i^{t h}$ node calculates the ratio of the $i^{t h}$ rule's firing strength to the sum of all the rule's firing strength. The outputs are called the normalised firing strengths.

$$
O_{3, i}=\hat{W}_{1}=\frac{w_{1}}{w_{1}+w_{2}}, \text { for } i=1,2
$$

Layer 4: Every node $I$ in the layer is an adaptive node with a node function.

$$
O_{4, i}=\hat{W}_{i} f_{i}=\hat{W}_{i}\left(P x+Q_{i} y+R_{i}\right)
$$

$\{\mathrm{p}, \mathrm{q}, \mathrm{r}\}$ is the parameter set for this node and can be referred to as consequent parameters.

Layer 5: The signal node in this layer is a fixed node labelled sum, which computes the overall output as the summation of all incoming signals. Overall output could be given as;

$$
O_{5, i}=\hat{W}_{i} f_{i}=\frac{\sum_{i} w_{i} f_{i}}{\sum_{i} w_{i}}
$$

\section{RESULTS AND DISCUSSION \\ 3.1 Effects of Burial Depth of Pipe}

Using the neuro-fuzzy plot, the average burial depth, and average corrosion rate shared similar line pattern that reflects the possibility of a correlation between burial depth of the metallic pipe and corrosion rate (Figures 34). The corrosion, however, reduces as the depth increases.

\subsection{Effects of Soil Type}

Figures 5-6 below displays the influence of soil type on corrosion rate. The corrosion rate decreased for first and second soil types, but the clay content does not show a consistent trend. However, a different pattern was found for the third to sixth soil types where the increment of clay content caused an increase in the corrosion rate observed. 


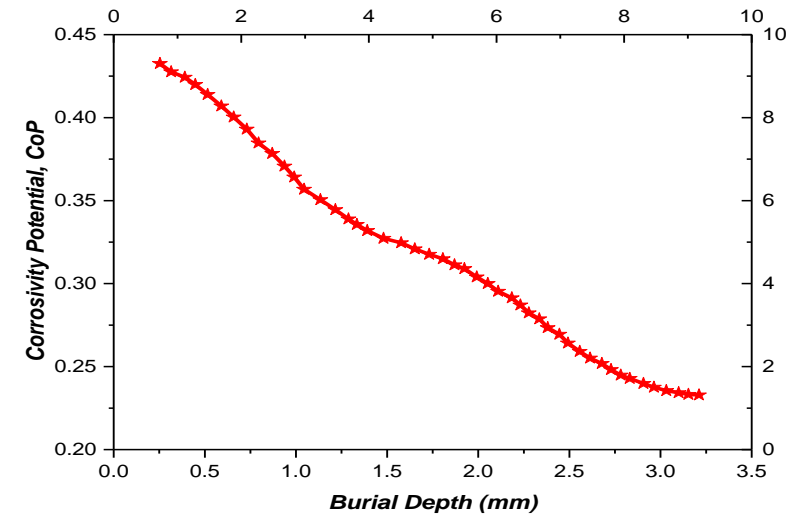

Figure 3: CoPagainst burial depth of pipes

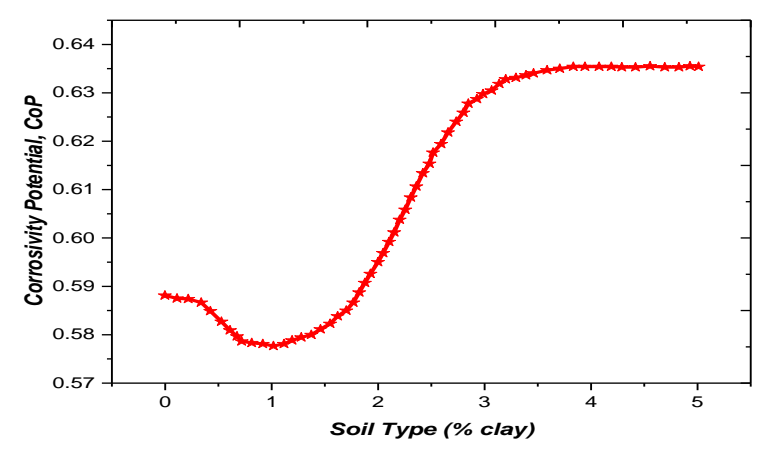

Figure 5: CoP against soil types

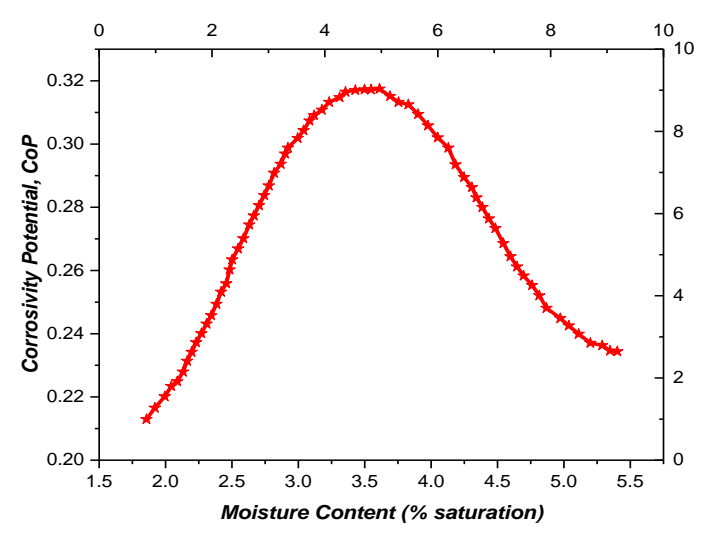

Figure 7: CoP against soil moisture content

\subsection{Effects of Moisture Content}

The average moisture content and average corrosion rate shared similar line pattern that reflects the possibility of a correlation between moisture content and corrosion rate (Figures 7-8). There is a direct proportionality between the index of corrosion and moisture content of the soil. Corrosion develops faster by higher moisture content [16]. Subsequently, decrease on the corrosivity as the moisture content rose above $60 \%$ was noticed. This could be however due to the learning capabilities of the ANFIS as no data was provided with a moisture content above $60 \%$.

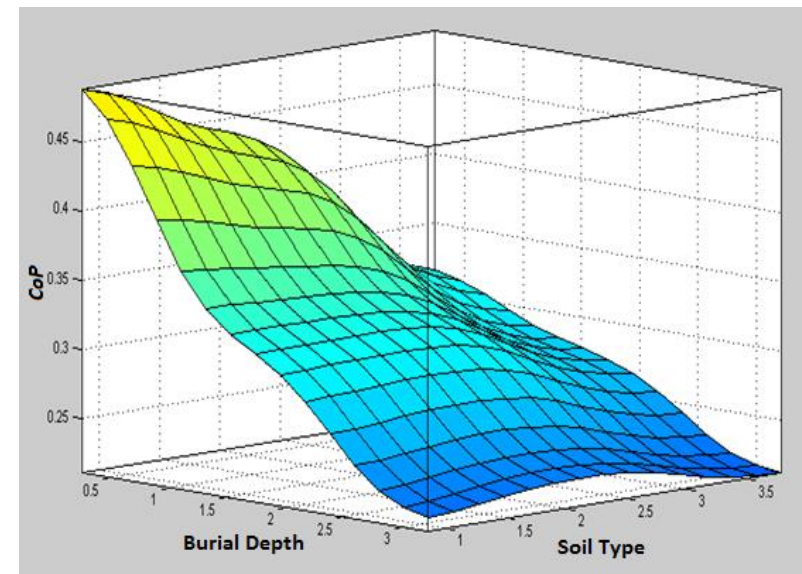

Figure 4: Surface plot of CoP against burial depth of pipes for different soil types

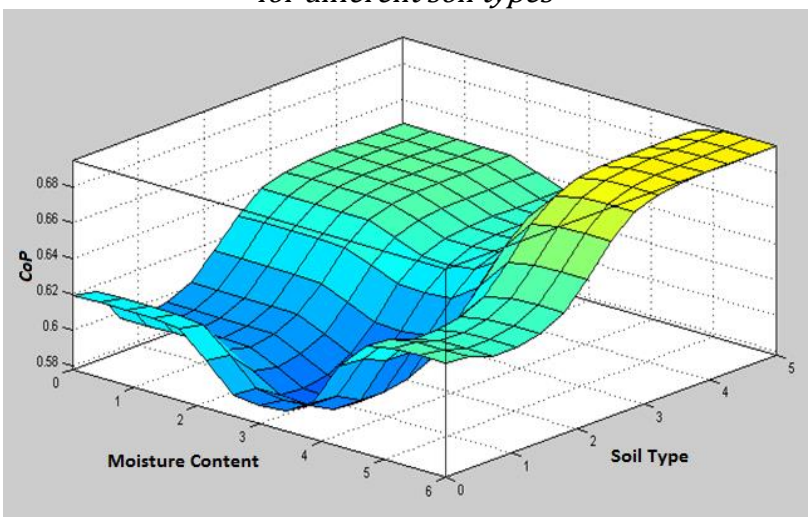

Figure 6: Surface plot of CoP against moisture content of the soil for different soil types

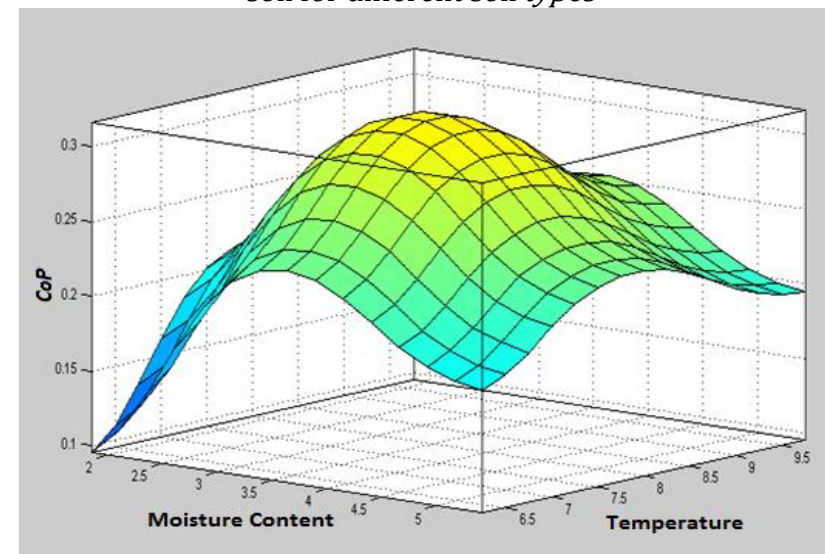

Figure 8: Surface plot of CoP against moisture content of the soil at different temperatures

\subsection{Effects of Soil pH}

The average corrosion rate, plotted against the soil $\mathrm{pH}$ shows a rather significant trend evident in Figures 9-10. The line pattern reveals that corrosion rate is maximum in acidic soils, with a $\mathrm{pH}$ value of about 5.0 and afterwards decreases as the $\mathrm{pH}$ tends to neutral then basic. The result shows that extremely acid soils (below pH 4.5) have significantly high corrosion loss rates when compared to other soils [17]. 


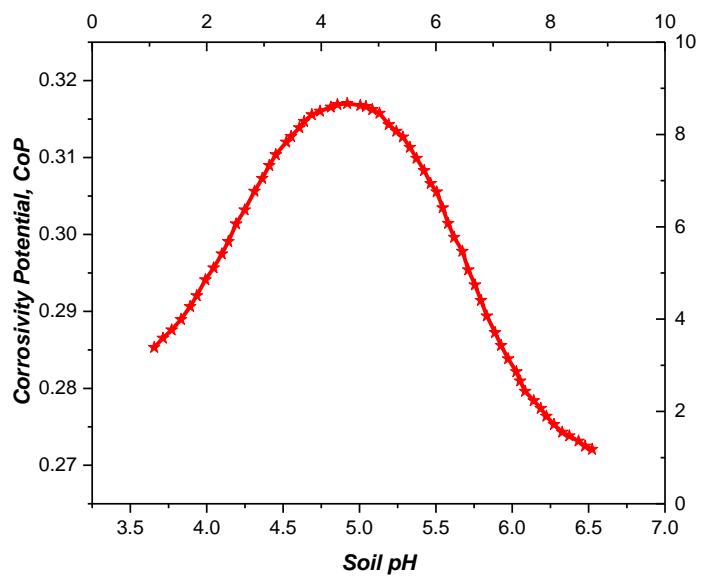

Figure 9: $C o P$ against soil $\mathrm{pH}$

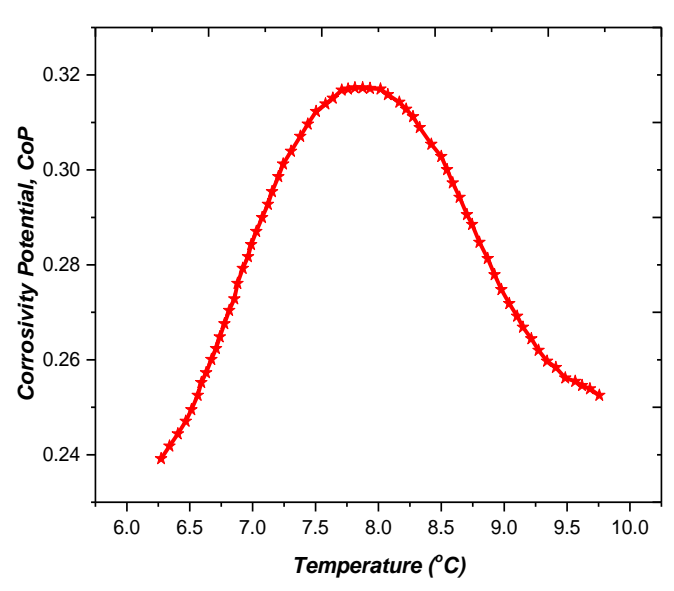

Figure 11: CoP against temperature

\subsection{Effects of Temperature}

From Figures 11-12, the corrosion rate increased significantly as temperature increased from $25{ }^{\circ} \mathrm{C}$ to about $45{ }^{\circ} \mathrm{C}$. With further increase in temperature, the corrosion rate decreased obviously. The corrosion rate could reach the maximum value at $50{ }^{\circ} \mathrm{C}$. These results indicate that metallic pipes are stable at very high temperatures.

The soil type and properties relations are plotted on the same axis as shown in Figure 13. The effect of soil type shows to be having more influence on the pipe deterioration more than other properties of the soil. The graph reveals that highest value of $C o P$ is 0.64 , when the soil that is harboring the metallic pipe has more than $40 \%$ clay content.

\subsection{Rules Based Reasoning}

The ANFIS combines both fuzzy logic principle and the concept of the neural networks. The ANFIS has advantages such as smoothness property from the fuzzy

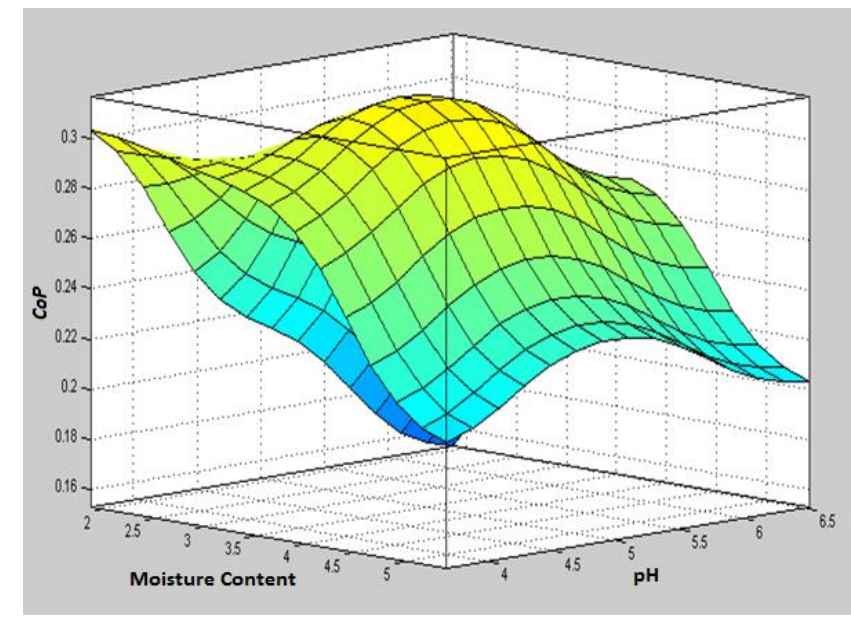

Figure 10: Surface plot of CoP against moisture content of the soil at different soil $\mathrm{pH}$

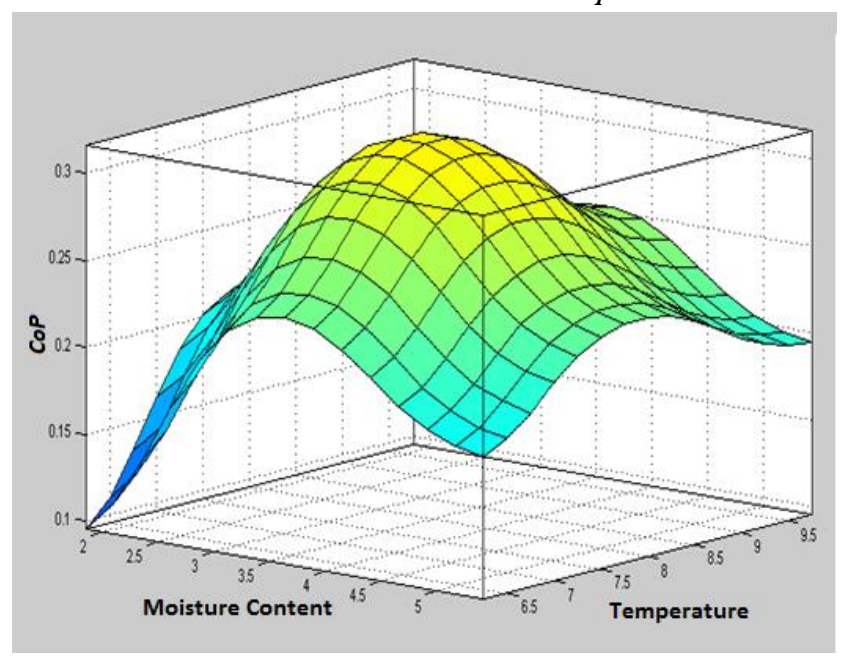

Figure 12: Surface plot of CoP against moisture content of the soil at different temperatures

principle and adaptability property from the neural networks training structure.

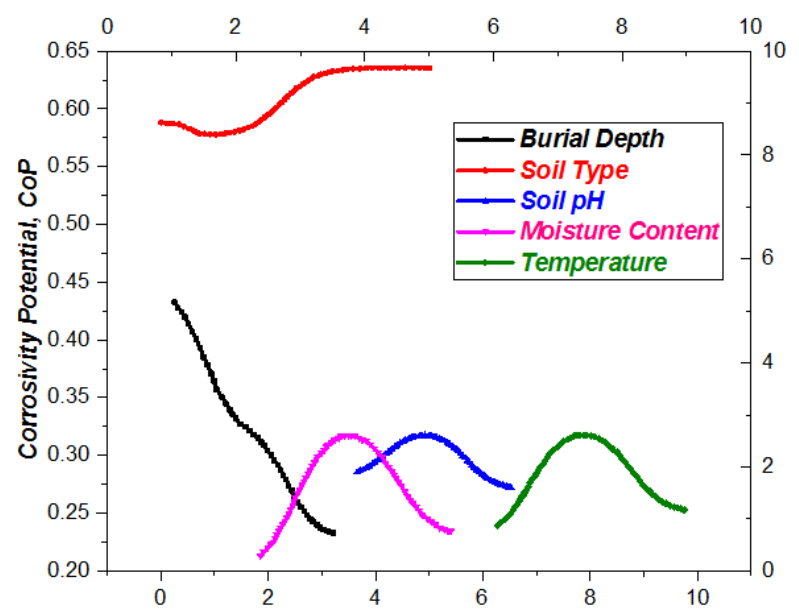

Figure 13: Surface plot of CoP against moisture content of the soil at different temperatures

Figure 13 is an extract of the fuzzified input / output parameters for the ANFIS implementation. Soil properties, pipe age, and maximum pit depth 
measurements available from a previous study on cast iron mains $[9,18]$ are used to validate the fuzzy model. The corrosion pitting growth is used as a criterion for deterioration rates $(D R)$. The soil properties and pit depth measurements are a snapshot of current conditions; and thus, deterioration rates obtained from maximum pit depth and pipe age, represent an average rather than maximum or instantaneous values. A partial list of $D R$ and $C o P$ values for a series of soil samples. Figure 14 shows the relationship between $D R$ and $C o P$ based on results obtained from the NFM. The plot suggests that the deterioration rate is "reasonably" correlated with $\operatorname{CoP}$, i.e., the higher the $\operatorname{CoP}$ the higher the $D R$ will be.

The relationship between the deterioration rate and $C o P$ as shown in Figure 14 may be approximated using a third order polynomial regression model that is given by;

$$
D R=b_{1}(C o P)-b_{2}\left(C o P^{2}\right)+b_{3}\left(C o P^{3}\right)
$$

Where $m$ and $C$ are the values of the slope and intercept of the line respectively.

Thus, for the linear relationship, the confidence interval for $D R$ can be estimated using normally distributed slope and intercept. The equation of the line shown in the Figure 14 is obtained based on the standard statistical tool imbedded in OriginLAB [19]. The regression equation is evaluated as;

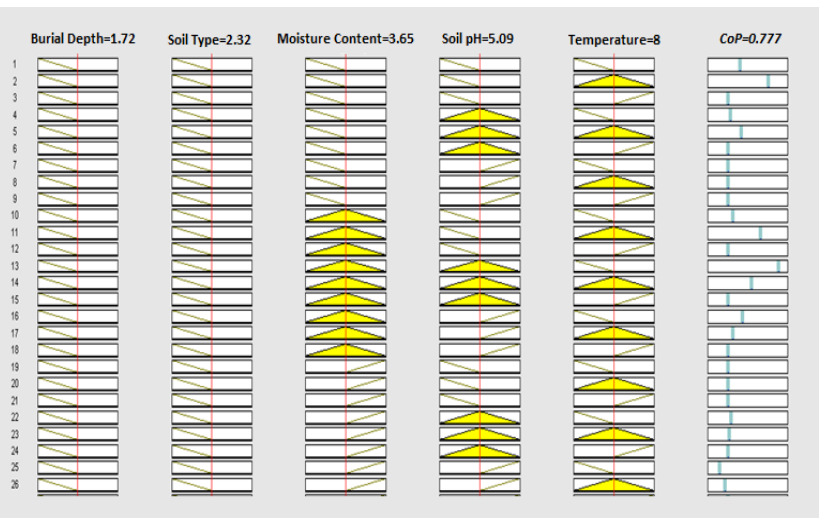

Figure 14: An Extract of the fuzzified input / output parameters

$$
D R=1.73(\mathrm{CoP})-3.33\left(\mathrm{CoP}^{2}\right)+2.10\left(\mathrm{CoP}^{3}\right)
$$

The Root Mean Square Error (RMSE) from Table 9 if evaluated as 0.021 . The statistical results had been obtained at $95 \%$ confidence level. The Model F-value of 2.1576 implies the model is significant. There is only a 0.09696 chance of getting a correlation of $R^{2}=0.05418$. The output $R^{2}$ value (0.05418) indicates the accuracy of the model.

Table 7: Statistical Output from the Polynomial Fitting

\begin{tabular}{ll}
\hline Output & Value \\
\hline Equation & $y=$ intercept $+b_{1} x+b_{2} x^{2}+b_{3} x^{3}$ \\
Weighting & No Weighting \\
Intercept & $-0.23147 \pm 0.16279$ \\
$b_{1}$ & $1.72585 \pm 0.98839$ \\
$b_{2}$ & $-3.33305 \pm 1.90653$ \\
$b_{3}$ & $2.09941 \pm 1.18392$ \\
Residual Sum of & 0.04823 \\
squares & 0.05418 \\
$C O D, R^{2}$ & 0.02907 \\
$A d j . R^{2}$ &
\end{tabular}

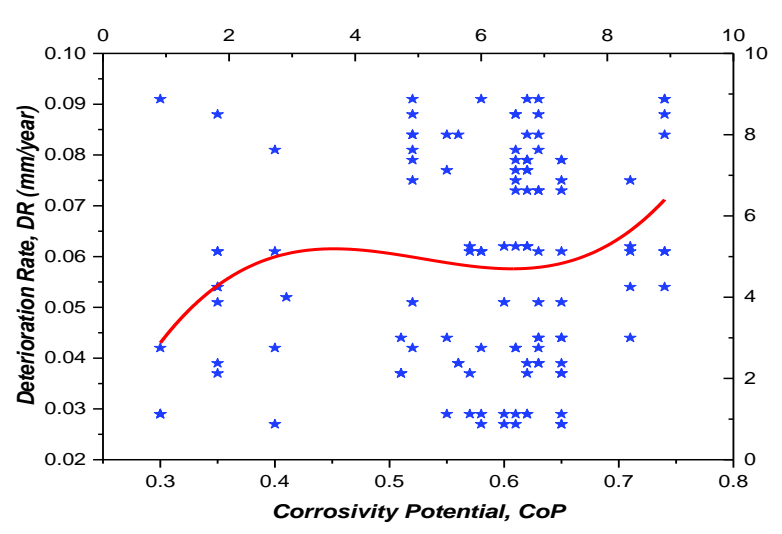

Figure 15: Correlation of DR and CoP

\begin{tabular}{|c|c|c|c|c|c|c|c|}
\hline \multicolumn{2}{|c|}{ intercept } & \multicolumn{2}{|r|}{$b_{1}$} & \multicolumn{2}{|c|}{$b_{2}$} & \multicolumn{2}{|c|}{$b_{3}$} \\
\hline $\begin{array}{c}\text { Value } \\
-0.23147 \\
\end{array}$ & $\begin{array}{c}\text { Standard Error } \\
0.162786 \\
\end{array}$ & $\begin{array}{c}\text { Value } \\
1.7258 \\
\end{array}$ & $\begin{array}{c}\text { Standard Error } \\
0.988392 \\
\end{array}$ & $\begin{array}{c}\text { Value } \\
-3.33304 \\
\end{array}$ & $\begin{array}{c}\text { Standard } \\
\text { Error } \\
1.906531 \\
\end{array}$ & $\begin{array}{c}\text { Value } \\
2.099407 \\
\end{array}$ & $\begin{array}{c}\text { Standard } \\
\text { Error } \\
1.18392 \\
\end{array}$ \\
\hline \multicolumn{8}{|c|}{ Table 9: Regression Analysis with Analysis of Variance (ANOVA) } \\
\hline & DF & & Sum of Squares & Mea & Square & F value & Prob $>F$ \\
\hline Regression & 3 & & 0.00276 & & 0921 & 2.1576 & 0.09696 \\
\hline Residual & 113 & & 0.04823 & & 0427 & & \\
\hline Total & 116 & & 0.051 & & & & \\
\hline
\end{tabular}

Table 8: Standard Errors of the Polynomial Fitting 


\section{CONCLUSIONS}

A neuro-fuzzy model is proposed to determine the deterioration rate of metallic fluid-conveying-pipe based on five soil types and properties. The NFM predicts a corrosivity potential $(C O P)$ for a given soil sample and uses a a third order polynomial model to link the $C O P$ value to deterioration rate. The model yields not only a fuzzified value of $C o P$ but also an output fuzzy set. The highest value of $C o P$ is 0.64 , when the soil that is harboring the metallic pipe has more than $40 \%$ clay content.

The results show that the aim of the research which is to develop a neuro-fuzzy model capable of establishing a criterion such as corrosion rate, and predicting the deterioration rate of metallic fluid-conveying-pipe using pipe burial depth, soil types, and properties have been achieved. Using Analysis of Variance (ANOVA), CoP effects are found to be a reliable index for measuring corrosion growth in buried pipes. Hence, the rate of deterioration of a metallic pipe conveying fluid is a function of the corrosivity potential.

It has also been shown that corrosivity potential could assist in cost-benefit analysis to determine the optimal level of corrosion protection require in a buried metallic pipe conveying fluid based on the enlisted soil properties.

\section{References}

[1] Fatmala N. "Offshore Pipeline Corrosion Prevention", http://nfatmala.blogspot.com.ng /2016/ 02/ offshore-pipeline-corrosion-prevention.html. 2016

[2] Tran, H.D., 2007, "Investigation of deterioration models for stormwater pipe systems," Ph.D. Thesis, Victoria University.

[3] Hasan, M.S. "Deterioration prediction of concrete bridge components using artificial intelligence and stochastic methods," Ph.D. Thesis, RMIT University, 2015.

[4] https://www.geoilandgas.com/sites/geog.dev. local/files/ge_pii_metalloss_jv_bim-112514.pdf. Accessed on November 10, 2016.

[5] Bardossy, A., Bronstert, A., and Merz, B. "1-, 2- and 3Dimensional modeling of groundwater movements in the unsaturated soil matrix using a fuzzy approach," Advances in Water Resources, Vol. 18(4), pp. 237251.

[6] Dou, C., Woldt, W., Bogardi, I., and Dahab, M., 1995, "Steady-state groundwater flow simulation with imprecise parameters," Water Resources Research, Vol. 31 (11), 27092719, 1995.
[7] Guyonnet, D. G., Come, B., Perrochet, P., and Parriaux, A. "Comparing two methods for uncertainty in risk assessments," ASCE Journal of Environmental Engineering, Vol. 125(7), pp. 660-666, 2000.

[8] Najjaran, H., Sadiq, R., and Rajani, B. "Fuzzy Logic Expert System for Assessing Corrosion of Cast/Ductile Iron Water Mains using Soil Properties," Proceedings of ASCE Pipelines200, San Diego, CA, 2004.

[9] Rajani, B., Makar, J., McDonald, S., Zhan, C., Kuraoka, S., Jen, C. K. and Veins, M. "Investigation of grey cast iron water mains to develop a methodology for estimating service life," American Water Works Association Research Foundation (AWWARF), Denver, CO, 2000.

[10] Seica, M. V., Packer J. A., Grabinsky M. W. F., Adams B. J., and Karney B. W. "Evaluation and testing of cast iron and ductile iron water mains samples," Final Report to City of Toronto, Department of Civil Engineering, University of Toronto, 2000.

[11] Kulkarni, R. B., Golabi, K., and Chuang, J. "Analytical techniques for selection of repair-orreplace options for cast iron gas piping systems Phase I," Gas Research Institute PB87-114112, Chicago, I1, 1986.

[12] Spickelmire, B. "Corrosion consideration for ductile iron pipe," Materials Performance, Vol. 41, pp. 16-23, 2002.

[13] Sugeno, M., and Yasukawa, T. "A fuzzy-logicbased approach to qualitative modeling," IEEE Transactions on Fuzzy Systems, Vol. 1(1), pp. 7-31, 1993.

[14] Yager, R. R., and Filev, D. P. "Essentials of fuzzy modeling and control," John Willey \& Sons Inc., NY, US, 1994.

[15] Yager, R. R., and Filev, D. P. “Template based fuzzy systems modeling," Journal of Intelligent Systems, Vol. 2, pp. 39-54, 1994.

[16] Norhazilan, M.N., Nordin, Y., Lim, K.S., Siti, R.O., Safuan, A.R.A. and Norhamimi, M.H., "Relationship between soil properties and corrosion of carbon steel". J. Applied Sci. Res, Vol. 8, 2012, pp.1739-1747.

[17] Chance Company, Helical Screw Foundation System Design Manual for New Construction, 2003, Hubbell, Inc

[18]Rajani, B., and Kleiner, Y. "Comprehensive review of structural deterioration of water mains: Physical based models," Urban Water, Vol. 3(3), pp. 151-164, 2001.

[19] originlab.com/ 